\title{
Research on Existing Problems and Reforms Related to the Teaching of Fundamentals of Machine Design
}

\author{
Zengsheng Wang \\ School of Mechanical Engineering \\ Huanghe Science and Technology College \\ Zhengzhou, China
}

\author{
Defeng Gao \\ School of Mechanical Engineering \\ Huanghe Science and Technology College \\ Zhengzhou, China
}

\author{
Hansong Yang \\ School of Mechanical Engineering \\ Huanghe Science and Technology College \\ Zhengzhou, China
}

\begin{abstract}
This article makes a summary to major problems existing in the traditional teaching of Fundamentals of Machine Design and collects typical patterns for the reform of Fundamentals of Machine Design in colleges arising in the past years, which to some degree play a role of enlightenment and reference in the course reform.
\end{abstract} quo

Keywords-Fundamentals of Machine Design; reform; status

\section{INTRODUCTION}

The Fundamentals of Machine Design is a technically important basic course required for machine or semi-machine major, it acts as a bridge between the previous and the next in teaching programs while training students in comprehensive design skills and innovation, shouldering the comprehensive application of lead courses (as mechanical drawing tolerance $\&$ fits, engineering materials, engineering mechanics and more) and placing a necessary foundation for the follow-up courses to form major concepts, methods and abilities of design thought. It is of not only strong theoretical property but also strong practicability and applicability. During the training of engineering and technical talents related to machine or semimachine, it works to intensify students' basic theories related to machine, raise students' applicability to mechanical and technical operation as well as train their abilities in development and innovation.

\section{PROBLEMS EXISTING IN THE TEACHING OF}

TRADITIONAL FUNDAMENTALS OF MACHINE DESIGN AND THE REFORM PATTERNS

Traditionally, during the teaching of Fundamentals of Machine Design, teachers mostly give lessons that students are negative to receive. Besides, there are a lot of detailed

The project is funded by Henan-Stationed Undergraduate Education Reform Pilot Specialty-Mechanical Design and Manufacturing and Automation, Henan- Stationed Comprehensive Specialty Reform Pilot-Mechanical Design and Manufacturing and Automation, Henan- Stationed Non-Governmental College Brand Specialty-Material Molding and Control Engineering projects. knowledge to learn but scattered in different chapters or sections which are relatively separated, and it's hard for students to create a systematic and complete knowledge system, as a result of it, the students are in a low enthusiasm to learn, unable to understand or form a relation between practical application and what they've learned, saying nothing of the training of vocational skills or innovation. With the problems mentioned above considered, in order to stir students' interests to learn and train their vocational skills and innovative concepts, a majority of colleges have conducted helpful explorations during the teaching reform of Fundamentals of Machine Design and achieved some effects, of which, typical teaching reform patterns are summarized and given as follows:

\section{A. Create a Teaching System of Fundamentals of Machine Design Featuring "Competition to Promote Learning”}

Reference [2] shows, some defects can be found in both the traditional teaching pattern of Fundamentals of Machine Design and the competition-based training pattern. Traditionally there are less practices for the Fundamentals of Machine Design and the theory teaching mainly adopt "lessons giving" method that students are negative to accept, and what they have learned are unable to meet the needs of enterprises, and the students training is blind and in lack of effectiveness. However, the short term and overloaded training patterns aiming at competitions are all a rush for rapid results, besides, just a few students can benefit from it. Therefore, in this article, a project-based teaching mode is adopted for the Fundamentals of Machine Design on the basis of the working process, where detailed knowledge and capability objectives required in the teaching program are rebuilt and the teaching is carried out via the completion of project tasks sourced from competitions or enterprise production. In the meantime, a teaching system is established with competitions made in the form of "Project Group Competition", "Enterprise Title Contest", "Mechanical and Design Innovation Competition" and so on. In order to guarantee the feasibility of the "Competition to Promote Learning", it establishes a 
competition encouragement and security mechanism such as "Credit Management for Participants", "Rules for Skill Competition Encouragement", "Teaching Hour Management" and so on. Credit substitute, class hour reward and so on are adopted to remove the worries of participants and advisors. And the teaching system of "Competition to Promote Learning" has integrated new elements such as abilities, skills and innovation needed for the vocational competitions to the routine teaching and the new ideas and methods make students much closer to actual production and also enhance the competitive level of the competitions.

\section{B. Application of Flip Classroom Teaching Mode in the Teaching of Fundamentals of Machine Design}

Generally, traditional teaching process consists of knowledge dissemination and knowledge internalization, the knowledge dissemination is realized in class by teachers; the knowledge internalization is realized often through homework, operation or practice by students after class. Yet the flip classroom overturns the mode, readjusting the time in class and after class and transferring the rights to study or not from teachers to students [3]. With the flip classroom adopted, the knowledge dissemination is completed before class via information technology, and the knowledge internalization is achieved through cooperating with classmates under the instruction of teachers in class [4]

Reference [5] takes "four-bar linkage mechanism" as an example, describing the teaching design and arrangement of three parts namely knowledge transfer before class, knowledge conversion in class and knowledge expansion after class. During the knowledge transfer before class, teachers push videos of Conditions for Cranks Existing in the Four-Bar Linkage Mechanism, Quick Return Characteristics and Characteristics of Force Transmission, relevant courseware, animation as well as learning guided plans to the cloud class platform for students to learn. During the knowledge internalization, first of all, a group representative will make replies to the problems given in the learning guided plan together with group discussions so $s$ to check and rate the learning effect before class. Next, take the "sewing machine pedal mechanism" to draw the class tasks, analyze, discuss the tasks and lead students for the implementation and rating, analysis and summarization. Finally according to rating results, instruct students to rate between or in groups. During the knowledge expansion after class, teachers will create an activity via the cloud-based class platform: take the Pro/E software to simulate and verify conditions for ranks existing in the four-bar linkage mechanism. The model will play an instructive role in the teaching of Fundamentals of Machine Design and similar courses under the flip classroom pattern.

\section{Teaching Reform of Fundamentals of Machine Design on the Basis of Training Innovation Capability}

Reference [6] points out problems can be found in students' innovation capabilities: first, some own some innovation capabilities, yet in the lack of confidence in it; second, the students have some quality in innovation, yet having no rational knowledge structure; third, the student have no consciousness of innovation, in the lack of innovative thought. The defects in the teaching of Fundamentals of Machine Design do bad to training students' capabilities in innovation, which are shown as: irrational course system, less practice courses; more theoretical knowledge taught, less design projects and experiments; the innovative content design is simple, having on systematic structure; teachers have inadequate consciousness of innovation and inefficiently grasp the dynamic development of production and study. With the problems above considered, this article raises suggestions for reforms in four aspects: (1) Proper adjustment of teaching contents: select more versions to form teaching notes of their own to disseminate theoretical knowledge and strengthen the teaching of mechanisms with the most creative thoughts; introduce an innovative mechanism grouping such as series and parallel mechanisms and make a systematic dissemination of innovative techniques. (2) Focusing on experiment teaching: increase experiment operations, introduce open experiments and improve students' abilities of creative design with the assistance of computers. (3) Creating an atmosphere for teaching: introduce students to develop the self innovation, encourage innovative ideas and help them modify and achieve innovation works. (4) Improvement of course design: convert the course design into project and product, the course design achievements shall be diverse, which can be works, survey reports or technical articles, etc, and the course design achievements will be evaluated via innovative thought, innovative consciousness and capabilities.

\section{Teaching Reform of Fundamentals of Machine Design Integrated to Modeling Software}

In order to increase students' interests and attract more to participate, Reference [7] et al integrate 3D modeling software Pro/E to the teaching of Fundamentals of Machine Design, optimize its teaching contents and select major cases and adopt a teaching-study-practice integration method to organize the class teaching and practice. In the meantime, it also creates a class hour distribution sheet for the Fundamentals of Machine Design, refer to "Table I".

TABLE I. CLASS HOUR DISTRIBUTION

\begin{tabular}{|c|c|c|c|c|}
\hline \multirow[t]{2}{*}{ No } & \multirow{2}{*}{ Item } & \multirow{2}{*}{$\begin{array}{l}\text { Class } \\
\text { Hour }\end{array}$} & \multicolumn{2}{|c|}{ Class Hour Distribution } \\
\hline & & & Teaching & Practice \\
\hline 1 & $\begin{array}{l}\text { Theoretical } \\
\text { mechanics }\end{array}$ & 15 & 9 & $\begin{array}{l}\text { Pro/E finite element } \\
\text { analysis, } 6 \text { hours }\end{array}$ \\
\hline 2 & $\begin{array}{l}\text { Mechanics } \\
\text { of materials }\end{array}$ & 15 & 9 & $\begin{array}{l}\text { Pro/E finite element } \\
\text { analysis, } 6 \text { hours }\end{array}$ \\
\hline 3 & $\begin{array}{l}\text { Link } \\
\text { mechanism }\end{array}$ & 6 & 2 & $\begin{array}{l}\text { Pro/E connecting rod } \\
\text { simulation, } 4 \text { hours }\end{array}$ \\
\hline 4 & $\begin{array}{l}\text { Gear } \\
\text { mechanism }\end{array}$ & 6 & 2 & $\begin{array}{l}\text { Pro/E cam molding, } 4 \\
\text { hours }\end{array}$ \\
\hline 5 & Gear & 12 & 6 & $\begin{array}{l}\text { Pro/E gear parameter } \\
\text { design, } 6 \text { hours }\end{array}$ \\
\hline 6 & Belt drive & 8 & 6 & $\begin{array}{lll}\begin{array}{l}\text { Molding } \\
\text { hours }\end{array} & \text { software, } & 2 \\
\end{array}$ \\
\hline 7 & Shaft & 12 & 6 & $\begin{array}{l}\text { Pro/E shaft structure } \\
\text { design and calibration, } 6 \\
\text { hours }\end{array}$ \\
\hline 8 & Jointing & 4 & 4 & 0 \\
\hline 9 & Reducer & 12 & 6 & Pro/E assembly, 6 hours \\
\hline & Total & 90 & 50 & 40 \\
\hline
\end{tabular}


Seen from "Table I", the course practice hours are much increased, up to $44.4 \%$. During the practice, the teaching is done via the flow "introduction to theory $\rightarrow$ student learning $\rightarrow$ teacher demonstration $\rightarrow$ followed by students $\rightarrow$ task arrangement $\rightarrow$ students do independently $\rightarrow$ summarized by teachers". The Pro/E practice is used to understand and intensify the boring theories, greatly raising students' interests in learning and making improvement in Pro/E application.

\section{E. Teaching Reform of Fundamentals of Machine Design on the Basis of CDIO}

The CDIO teaching is an engineering educational idea created by four universities including Massachusetts Institute of Technology, namely Conceive-Design-ImplementOperate, which is an embodiment of the project-base teaching and the principle "learn in operation, and operate in learning".

Reference [8] gives a detailed explanation for the CDIO applied in the teaching of Fundamentals of Machine Design for project carrier selection, conditions for implementation and implementation course design. During the teaching, guided by the working process, 10 project carriers are designed: Project 1: Design of movement conversion mechanism; Project 2: Design of domestic sewing machine assembly / disassembly or design of slider crank mechanism assembly / disassembly in internal combustion engine; Project 3: Design of power input or design of disc cam mechanism in the valve mechanism; Project 4: common V-belt drive of bench drilling machine; Project 5: Gear design; Project 6: shaft system design; Project 7: Assembly / disassembly of fixed connections; Project 8: Bicycle design; Project 9: Design of overall reducer; Project 10: Design of belt conveyor gearing. Take carriers like singlecylinder internal combustion engine, lift pump, domestic sewing machine, valve mechanism of internal combustion engine, jaw crusher, bicycle, straight column gear reducer, and start from easy to difficult, a spiral progress to achieve the design of teaching contents. The project carriers mentioned above deserve references.

\section{F. Teaching Reform of Fundamentals of Machine Design for A Given Industry}

References [9-11] discuss the teaching of Fundamentals of Machine Design course relative to industrial projects. Reference [8] classifies on-the-spot mechanical equipment of steel and metallurgy as per functions into three projects namely lifting transport machine, ventilation and air conditioning machine, packaging and warehousing machine. In the meantime, it divides the Fundamentals of Machine Design course as per mechanical functions and applications into five sub-modules including commonly used mechanism, mechanical drive, bearing parts, connection and comprehensive training. And the sub-modules will be applied during the project teaching. Reference [9]: as per the frequently used spare parts of mining machines, it designs four projects namely the assembly / disassembly/analysis of cylinder gear speed reducer, the assembly / disassembly/analysis of small fan gearing-gearing, the assembly / disassembly/analysis of mineral-based coupling as well as the assembly / disassembly/analysis of mine hoistbased commonly closed rear cylinder disc brake. Reference
[10], with the mould major considered, it matches the contents of two typical equipment including crank press and plastic injection molding machine with the Fundamentals of Machine Design for teaching. The teaching reform connecting with the industry embodies the features of major courses, doing good to training students in vocational skills. However, it still needs to develop corresponding textbooks with double-position teachers arranged.

\section{CONCLUSION}

In conclusion, the teaching reform of Fundamentals of Machine Design in any form is to train students to acquire corresponding knowledge, abilities and quality. Main methods in reforms are to stir students' enthusiasm as possible as they can and bring them chances for discussion, exchange and thought, where teachers mainly act as instructors. The final way for the reform is to implement the project teaching, with the projects taken as carriers, during the completion of the projects, students may acquire knowledge, create connections between key knowledge, theories and practice so as to form a systematic knowledge system, acquiring vocational abilities, teamwork spirit and consciousness of innovation.

\section{REFERENCES}

[1] Chen Meigan, Teaching Development of Fundamentals of Machine Design Highlighting Features of High Vocational Education [J]. Science and Technology, 2016,(20):210-211.

[2] Qin Lili, Building a Teaching System of Fundamentals of Machine Design based on "Competition to Promote Learning"

[3] He Kekang, Analyzing the Nature of Flip Classroom to Overlook its Development in China [J]. E-education Research, 2014,(07):5-16.

[4] Zhang Yueguo, Zhang Yujiang, Insight into the "Flip Classroom" [J]. Information Technology Education in Primary and Middle Schools, 2012,(03):9-10

[5] Jing Juan, Cao Ruixiang, Cheng Zhiqing, Design and Application of Flip Classroom Pattern in Fundamentals of Machine Design of High Vocational Education [J]. Learning Weekly, 2016,(29):33-34

[6] Zhao Mingzhen, Problems and Countermeasures Concerned in Training Students' Innovation Abilities of Electromechanical in High Vocational Education [J] Modern Manufacturing Technology and Equipment, 2014,(05):79-80.

[7] Xiao Suhua, Chen Jianhuan, Teaching Reform and Practice of Fundamentals of Machine Design Integrated to Modeling Software in High Vocational Education [J]. Mechanical Vocational Education, 2014, (05):47-48.

[8] Pu Yi, Teaching Reform and Practice of CDIO-based Fundamentals of Machine Design Teaching in High Vocational Colleges [J]. Mechanical Vocational Education, 2014,(11):43-45.

[9] Hou Changlai, Primary Discussion on Teaching of Fundamentals of Machine Design Connected with Projects [J]. Journal of Liaoning Institute of Science and Technology, 2016,(03):46-47.

[10] Song Juling, Li Jingfei, Zheng Liwei, Xin Hua, Reform and Practice of Fundamentals of Machine Design Teaching on the Basis of Training Vocational Skills [J]. Career Horizon, 2016,(03):64-66.

[11] Xu Ying, Lan Jie, Reform of Fundamentals of Machine Design Aiming Mould Specialty in High Vocational Education, 2015,(02):23-25. 